\title{
Light-Controlled Molecular Switches Modulate Nanocrystal
}

\section{Fluorescence}

\author{
Linyong Zhu, Ming-Qiang Zhu, James K. Hurst, and Alexander D.Q. Li \\ Department of Chemistry and Center for Materials Research, Washington State University, Pullman, \\ WA 99164 E-mail : dequan@wsu.edu
}

There is considerable current interest within the rapidly expanding field of nanotechnology ${ }^{1}$ in integrating hard and soft structures into complex functional nanosystems that have stimuli responsive properties. ${ }^{2}$ Control of nanoscale "devices" fabricated from these materials is one of the major challenges limiting their implementation. Indeed, size constraints render physical contacts to nanoscale devices inherently ambiguous, making them difficult to "wire". An alternative approach to addressing nanoscale devices is via the photon, which obviously requires no physical contacts. Herein we report a hard-and-soft hybrid nanosystem whose fluorescence intensity can be reversibly modulated using specific bandwidths of light. Specifically, we have attached a spiropyran via a thiol-metal linkage to a core-shell semiconductive $\mathrm{CdSe} / \mathrm{ZnS}$ nanocrystal. Preparation of both the spiropyran and the core-shell nanocrystals is straightforward and follows reported procedures; ${ }^{3}, 4$ the hybrid spiropyrannanocrystal systems used in these studies were constructed by simply mixing the nanocrystals with the thiolated spiropyran.

The emission intensity of underivatized fluorescent nanocrystals cannot be modulated. However, nanocrystals functionalized with spiropyrans gain on-off function that arises from the photoisomerization capabilities of the bound chromophore (Scheme 1). Spiropyrans undergo photoinduced ring opening reactions under ultraviolet irradiation to give isomeric merocyanine dyes that have strong solvatochromic absorption bands in the visible spectral region; the band maximum for the particular compound under study, 5-(1,3-dihydro-3,3dimethyl-6-nitrospiro[2H-1-benzopyran-2,2'-(2H)-indole])hexane-1-thiol, appeared at 580 $\mathrm{nm}$ in THF. The origin of this band is the extended $\pi$-conjugation that develops between the indolene and pyran rings following rupture of the $\mathrm{C}-\mathrm{O}$ (spiro) bond. Back-conversion from the mero forms of the dye to the spiro form occurs thermally and is accelerated by excitation into the visible band. ${ }^{5}$ This conformational change has been used to alter the physical and chemical properties of materials, including emission from organic dyes. ${ }^{6}$ The spiropyran-functionalized nanocrystals exhibited light-induced reversible photochromism that was very similar to the photochromism exhibited by the unbound dye (Figure 1A). However, fluorescence from the hybrid nanocrystals that was observed when the dye was in its spiro form was strongly quenched by the dye in its mero form, which absorbs maximally at $588 \mathrm{~nm}$ when bound to the particles. This effect is illustrated in Figure 1B, where the fluorescence intensity of the dyefunctionalized nanocrystals has been modulated with alternating cycles of UV $(350 \mathrm{~nm})$ and visible $(588 \mathrm{~nm}$ ) light. For several cycles, at least, this modulation was fully reversible, demonstrating the potential of such hybrid nanosystems for on-and-off switching applications.

In these hybrid constructs, photon energies that effect dye photoisomerization and induce particle fluorescence are well-resolved, allowing clean separation between photoinduced molecular switching and fluorescence excitation. Specifically, the spiro form can be converted

Supporting Information Available: Syntheses, characterization, and optical properties of hybrid spiropyran-nanocrystals. 
to the mero isomers by photoexcitation with UV light within a $260-390 \mathrm{~nm}$ range, the optimum wavelength being $350 \mathrm{~nm}$, which is the absorption maximum of the spiro form. Conversely, visible light at wavelengths greater than $515 \mathrm{~nm}$ effect mero- to spiro-switching, the most effective wavelength being $588 \mathrm{~nm}$. In contrast, fluorescence excitation of the nanocrystal is insensitive to wavelength over a wide spectral range throughout the visible and UV region. By selecting a wavelength of $\sim 420 \mathrm{~nm}$, one can elicit particle fluorescence without simultaneously inducing molecular switching, that is, without modulating its intensity by simultaneously altering the relative amounts of spiro and mero forms of the bound dye. Because in these assemblies neither spiro nor mero forms emit light strongly, the dominant emitter was the nanocrystal, whose emission intensity is inversely dependent upon the amount of the mero form that is present.

We attribute this fluorescence quenching to fluorescence resonance energy transfer (FRET) from the nanocrystal to the merocyanine. In the spiro form, however, no FRET occurs because the strong visible band associated with the mero form is absent; consequently, under these conditions, emission from the particle is unquenched. The efficiency of FRET is largely governed by the extent of overlap between the emission band of the CdSe/ZnS energy donor and the absorption band of the merocyanine energy acceptor. The emission wavelength is dependent upon the particle size. For example, a $6 \mathrm{~nm}$ particle containing a $2.6 \mathrm{~nm}$ diameter CdSe core with $1.7 \mathrm{~nm}$ thick $\mathrm{ZnS}$ shell emits maximally at $578 \mathrm{~nm}$, which matches well the absorption band of the particle-bound merocyanine (Figure 2A), whereas smaller particles with 5 and $4 \mathrm{~nm}$ diameters containing a $2.4 \mathrm{~nm}$ diameter core and $1.3 \mathrm{~nm}$ thick shell or a $2 \mathrm{~nm}$ diameter core with $1 \mathrm{~nm}$ thick shell fluoresce maximally at $546 \mathrm{~nm}$ and $523 \mathrm{~nm}$, respectively. The emission bands of these particles overlap less strongly the absorption band of the merocyanine than does the larger particle; consequently, if FRET is the mechanism, fluorescence quenching by the merocyanine in these hybrid particles should become progressively less efficient as the particle size decreases. As illustrated in Figure 2B. this behavior was observed.

Also plotted in Figure 2B is the observed quenching efficiency using hybrid nanocrystals containing variable amounts of bound spiropyran. For the $6 \mathrm{~nm}$ hybrid nanocrystal, 90-100 bound dye molecules were required to attain maximal quenching; the smaller particles required progressively greater numbers of bound dye to reach equivalent quenching. Under the applied steady-state illumination conditions, $\sim 40 \%$ of the dye molecules were converted to the mero form, based upon the intensity of the visible absorption band. At higher dye loadings, the actual number of bound spiropyran molecules per particle were greater than the number required to effectively quench particle fluorescence; consequently, fatigue effects that were manifested in loss of intensity of the merocyanine visible bands upon repetitive cycling (Figure 1A and Supporting Information) were not reflected in the corresponding fluorescence emission intensities from the dye-bound particles, which remained constant over an equivalent number of cycles (Figure 1B).

These fatigue effects, which are a common feature found among a much wider range of organic photochromic compounds, are caused by photodegradation of the dyes under UV irradiation. Both $\mathrm{O}_{2}$-dependent and $\mathrm{O}_{2}$-independent mechanisms have been identified; ${ }^{9}$ for spiropyrans the $\mathrm{O}_{2}$-independent mechanism appears to be dominant, with degradation occurring primarily from the triplet manifold. ${ }^{8 a},{ }^{9 a}$ Consistent with this assignment, the rate of photodegradation in several environments has been found to increase with the dye concentration. ${ }^{8 a}$, 9 Our observations on the nature of photodamage of nanocrystal-bound spiropyran are consistent with these general observations. Specifically, prior irradiation under visible light for periods up to one hour caused no loss in the amount of dye converted to the mero form upon subsequent UV irradiation, as measured by the maximal photostationary absorbance achieved at $588 \mathrm{~nm}$. Therefore, visible light did not contribute to the observed photoinduced chemical degradation 
(Fig. 1A). In contrast, under continuous UV illumination $(260 \sim 390 \mathrm{~nm}, 0.97 \mathrm{~mW})$, the OD at $588 \mathrm{~nm}$ of mero-form faded at a rate that was dependent upon both the light intensity and the level of dye coverage on the nanocrystals. This fading rate was relatively insensitive to the presence of $\mathrm{O}_{2}$; for example, the initial fading rate of $2.6 \times 10^{-7} \mathrm{M} 6 \mathrm{~nm}$ particles containing 105:1 dye molecules was increased by only $\sim 33 \%$ when Ar-purged solutions were made aerobic. The apparent quantum yields for photodegradation estimated from the rate of loss of the merocyanine visible absorption band $\left(\varepsilon_{588}=3 \times 10^{4} \mathrm{M}^{-1} \mathrm{~cm}^{-1}\right)$ under continuous UV illumination were $\sim 5 \times 10^{-3}, \sim 6.4 \times 10^{-3}$, and $\sim 8.5 \times 10^{-3}$ for loadings of 26,65 , and 105 dye molecules, respectively, on $6 \mathrm{~nm}$ particles. Assuming a random distribution of dye molecules on the surface, these loadings correspond to surface densities of $1.1 \mathrm{~nm}^{2} / \mathrm{SP}, 1.7 \mathrm{~nm}^{2} / \mathrm{SP}$, and $4.4 \mathrm{~nm}^{2} / \mathrm{SP}$, respectively, or average separation distances of $1.2,1.5$, and $2.3 \mathrm{~nm}$. These distances are about the same as the lengths of thioalkane tethers to the dye chromophores, suggesting that surface bimolecular reactions between triplet excited dye molecules with neighboring dye molecules can occur without aggregation of the dye on the nanocrystalline surface. Decreasing the incident light intensity $\left(1.8 \times 10^{-9}\right.$ einstein/s) by $60 \%$ caused the initial rate of photodegradation to decrease by approximately one-half, indicating that the apparent quantum yield was not dependent upon the intensity. The photodegradation rate was also indistinguishable for $2.6 \times 10^{-5} \mathrm{M}$ dye in solution and when bound to $6 \mathrm{~nm}$ nanocrystals under identical irradiation conditions. These properties indicate that the photodegradation characteristics of the dye on these composite semiconductor particles is very similar to that described in other media; in particular, there is no indication that binding either enhances or retards photodegradation, e.g, as might occur by charge injection into the conduction band of the particle.

The inherent rate constants for photoinitiated spiro-mero interconversion are extremely large, with half-times typically on sub-picosecond timescales. ${ }^{10}$ However, under the prevailing experimental conditions, $\sim 5 \mathrm{~s}$ illumination was required to quench fluorescence and $\sim 90 \mathrm{~s}$ to reverse the process. (The time course of fluorescence quenching under UV photoexcitation is shown in Figure 1B as an overlay on the light-dark cycle intensities). The factors contributing to the much slower rate of fluorescence switching in the hybrid dyenanocrystals have not yet been identified but, because photoisomerization quantum yields are generally $\leq 0.6,{ }^{10 \mathrm{e}}$ probably reflect the need for multiple isomerizations to effectively quench the particle fluorescence.

To probe the impact of constraining the dye to the particle surface, we compared the quenching efficiencies of the thiol-containing spiropyran to an analog lacking this functionality. Figure $2 \mathrm{C}$ displays Stern-Volmer plots (defined as $I_{\mathrm{O}} / I=1+K_{\mathrm{sv}}$ [merocyanine]) of nanocrystals containing attached spiropyran and of physical mixtures of nanocrystals and the thiol-deficient spiropyran. The apparent Stern-Volmer constant measured for the bound dye was $K_{\mathrm{sv}}=9.3 \times$ $10^{4}, \sim 7$-fold greater than for the physical mixture $\left(K_{\mathrm{sv}}=1.4 \times 10^{4}\right)$, indicating considerably greater quenching efficiencies for the bound dye. This difference may reflect the closer proximity of the bound dye to the particle; the absorption band of the bound merocyanine was red-shifted by $8 \mathrm{~nm}$ from that in solution, presumably due to a nonpolar microenvironment on the particle surface. ${ }^{11}$ This shift caused poorer donor-acceptor spectral overlap of the bound merocyanine which, in the absence of countervailing factors, would have caused less efficient FRET to the bound dye.

These studies demonstrate that optical modulation of nanoparticle fluorescence is possible, suggesting potential application to optically addressable devices. One major obstacle to technological implementation of assemblies incorporating photoisomerizable dyes, however, has been the extensive photodegradative side reactions that accompany UV illumination. Strategies that have been used to minimize these reactions include maintaining anaerobic environments, ${ }^{8 \mathrm{a}}$ appending to the dye molecules that can function as triplet excited state, ${ }^{1} \Delta$ 
$\mathrm{O}_{2}$, or free radical quenchers, ${ }_{13}^{8 b}, 12$ and identifying classes of photochromic molecules that are unusually resistant to fatigue. ${ }^{3}$ In the present case, shortening the thioalkyl linker group on the immobilized dye may also significantly improve fatigue resistance by restricting degradative bimolecular reaction pathways.

\section{Supplementary Material}

Refer to Web version on PubMed Central for supplementary material.

\section{ACKNOWLEDGMENT}

We gratefully acknowledge the support of the DOE, Office of Basic Energy Sciences, Division of Chemical Sciences (Grant DE-FG03-99ER14943 to JKH) and Division of Materials Science and Engineering, National Institute of General Medical Sciences (Grant GM065306 to ADQL); ADQL is a Beckman Young Investigator.

\section{REFERENCES}

1. (a) Daniel MC, Astruc D. Chem. Rev 2004;104:293-346. [PubMed: 14719978] (b) Whetten RL, Shafigullin MN, Khoury JT, Schaaff TG, Vezmar I, Alvarez MM, Wilkinson A. Acc. Chem. Res 1999;32:397-406. (c) Rabani E, Hetenyi B, Berne BJ, Brus LE. J. Chem. Phys 1999;110:5355-5369. (d) Elghanian R, Storhoff JJ, Mucic RC, Letsinger RL, Mirkin CA. Science 1997;277:1078-1081. [PubMed: 9262471] (e) Mitchell GP, Mirkin CA, Letsinger RL. J. Am. Chem. Soc 1999;121:81223. (f) Maxwell DJ, Taylor JR, Nie SM. J. Am. Chem. Soc 2002;124:9606-9612. [PubMed: 12167056] (g) Wang W, Li LS, Helms G, Zhou HH, Li ADQ. J. Am. Chem. Soc 2003;125:1120-1121. [PubMed: 12553785] (h) Wang W, Wan W, Zhou HH, Niu SQ, Li ADQ. J. Am. Chem. Soc 2003;125:52485249. [PubMed: 12720416]

2. (a) Zhu M-Q, Wang L-Q, Exarhos GJ, Li ADQ. J. Am. Chem. Soc 2004;126:2656-2657. [PubMed: 14995155] (b) Redl FX, Cho KS, Murray CB, O'Brien S. Nat 2003;423:968-971. (c) Lai CY, Trewyn BG, Jeftinija DM, Jeftinija K, Xu S, Jeftinija S, Lin VSY. J. Am. Chem. Soc 2003;125:4451-4459. [PubMed: 12683815] (d) Kim JH, Lee TR. Chem. Mater 2004;16:3647-3651. (e) Gao JM, Watanabe S, Kool ET. J. Am. Chem. Soc 2004;126:12748-12749. [PubMed: 15469249]

3. (a) Mahima BS, Thomas KG. J. Am. Chem. Soc 2003;125:7174-7175. [PubMed: 12797780] (b) Doron A, Katz E, Tao G, Willner I. Langmuir 1997;13:1783-1790.

4. (a) Li J, Wang A, Guo W, Keay JC, Mishima TD, Johnson MB, Peng X. J. Am. Chem. Soc 2003;125:12567-12575. [PubMed: 14531702] (b) Yu WW, Qu L, Guo W, Peng X. Chem. Mater 2003;15:2854-2860.

5. Crano, JC.; Guglielmetti, RJ., editors. Organic Photochromic and Thermochromic Compounds. Plenum Press; New York: (b) Berkovic G, Krongauz V, Weiss V. Chem. Rev 2000;100:1741-1754. [PubMed: 11777418]Guglielmetti, R. Photochromism: (Revised Ed.). Dür, H.; Bouas-Laurent, TH., editors. Elsevier; Amsterdam: p. 855-878. (d) Minkin VI. Chem Rev 2004;104:2751-2776. [PubMed: 15137806]

6. (a) Giordano L, Jovin TM, Irie M, Jares-Erijman EA. J. Am. Chem. Soc 2002;124:7481-7489. [PubMed: 12071757] (b) Norsten TB, Branda NR. J. Am. Chem. Soc 2001;123:1784-1785. [PubMed: 11456790] (c) Guo X-F, Zhang D-Q, Zhu D-B. Adv. Mater 2004;16:125-130. (d) Bahr JL, Kodis G, de la Garza L, Lin S, Moore AL, Moore TA, Gust D. J. Am. Chem. Soc 2001;123:7124-7133. [PubMed: 11459493]

7. (a) Clapp AR, Medintz IL, Mauro JM, Fisher BR, Bawendi MG, Mattoussi H. J. Am. Chem. Soc 2004;126:301-310. [PubMed: 14709096] (b) Willard DM, Carillo LL, Jung J, Van Orden A. Nano Lett 2001;1:469-474. (c) Pinaud F, King D, Moore HP, Weiss S. J. Am. Chem Soc 2004;126:61156123. [PubMed: 15137777]

8. (a) Matsushima R, Nishiyama M, Doi M. J. Photochem. Photobiol. A: Chem 2001;139:63-69. (b) Li XL, Li JL, Wang YM, Matsuura T, Meng JB. J. Photochem. Photobiol. A: Chem 2004;161:201-213.

9. (a) Sakuragi M, Aoki K, Tamaki T, Ichimura K. Bull. Chem. Soc. Jpn 1990;63:74-79. (b) Baillet G, Giusti G, Guglielmetti R. Bull. Chem. Soc. Jpn 1995;68:1220-1225. (c) Baillet G, Campredon M, Guglielmetti R, Giusti G, Aubert C. J. Photochem. Photobiol., A: Chem 1994;83:147-51. (d) Baillet G, Giusti G, Guglielmetti R. J. Photochem. Photobiol. A: Chemistry 1993;70:157-61. 
10. (a) Wilkinson F, Worral DR, Hobley J, Jansen L, Williams SL, Langley AJ, Matousek P. J. Chem. Soc., Faraday Trans 1996;92:1331-1336. (b) Zhang JZ, Schwartz BJ, King JC. J. Am. Chem. Soc 1992;114:10921-10927. (c) Tamai N, Matsuhara H. Chem. Phys. Lett 1992;191:189-194. (d)

Ernsting NP, Athern-Engeland T. J. Phys. Chem 1991;95:5502-5509. (e) Guglielmetti R. Stud. Org. Chem 1990;40:855-878.

11. (a) Khairutdinov RF, Giertz K, Hurst JK, Voloshina EN, Voloshin NA, Minkin VI. J. Am. Chem. Soc 1998;120:12707-12713. (b) Pozzo J-L, Samat A, Guglielmetti R, De Keukeleire D. J. Chem. Soc., Perkin Trans. 2 1993:1327-1332.

12. (a) Campredon M, Luccioni-Houze B, Giusti G, Lauricella A, Alberti D, Macciantelli J. J. Chem. Soc., Perkin Trans. 2 1997:2559-2566. (b) Malatesta V, Milosa M, Millini R, Lanzini L, Bortolus P, Monti S. Mol. Cryst. Liq. Cryst 1994;246:287-290.

13. Masahiro I. Chem. Rev 2000;5:1685-1716. 


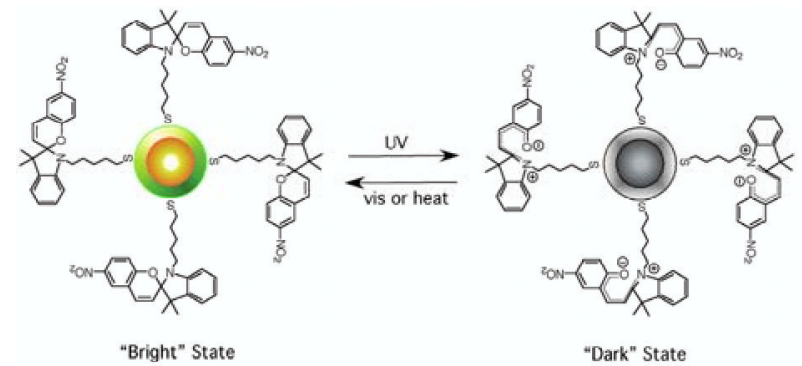

Scheme 1. 

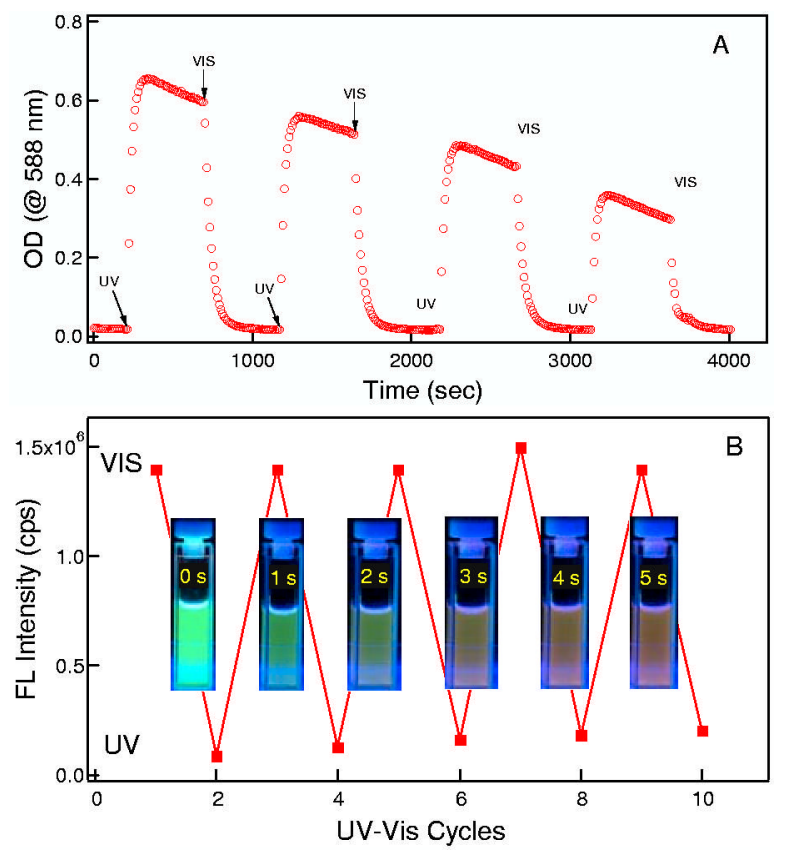

Figure 1.

Optical properties of deoxygenated solutions containing spiropyran (SP)-modified CdSe/ZnS core-shell nanocrystals (NC): (A) Photochromism of 6-nm CdSe/ZnS core shell nanocrystals at $2.6 \times 10^{-7} \mathrm{M}$ concentration with a SP/NC ratio of 105 under alternating cycles of filtered UV and visible illumination. (B) Modulation of the intensity of fluorescence emission at 546 $\mathrm{nm}$ with alternating cycles of UV and visible light (squares and lines); the size of core-shell $\mathrm{CdSe} / \mathrm{ZnS}$ nanocrystals is $5 \mathrm{~nm}$, the nanocrystal concentration is $3.5 \times 10^{-7} \mathrm{M}$, and the SP/NC ratio is 150. Overlay: Six cuvettes showing the response time at one-second intervals for conversion from the spiro to the mero form under $365 \mathrm{~nm}$ UV illumination. Illumination conditions are described in Supporting Information. 

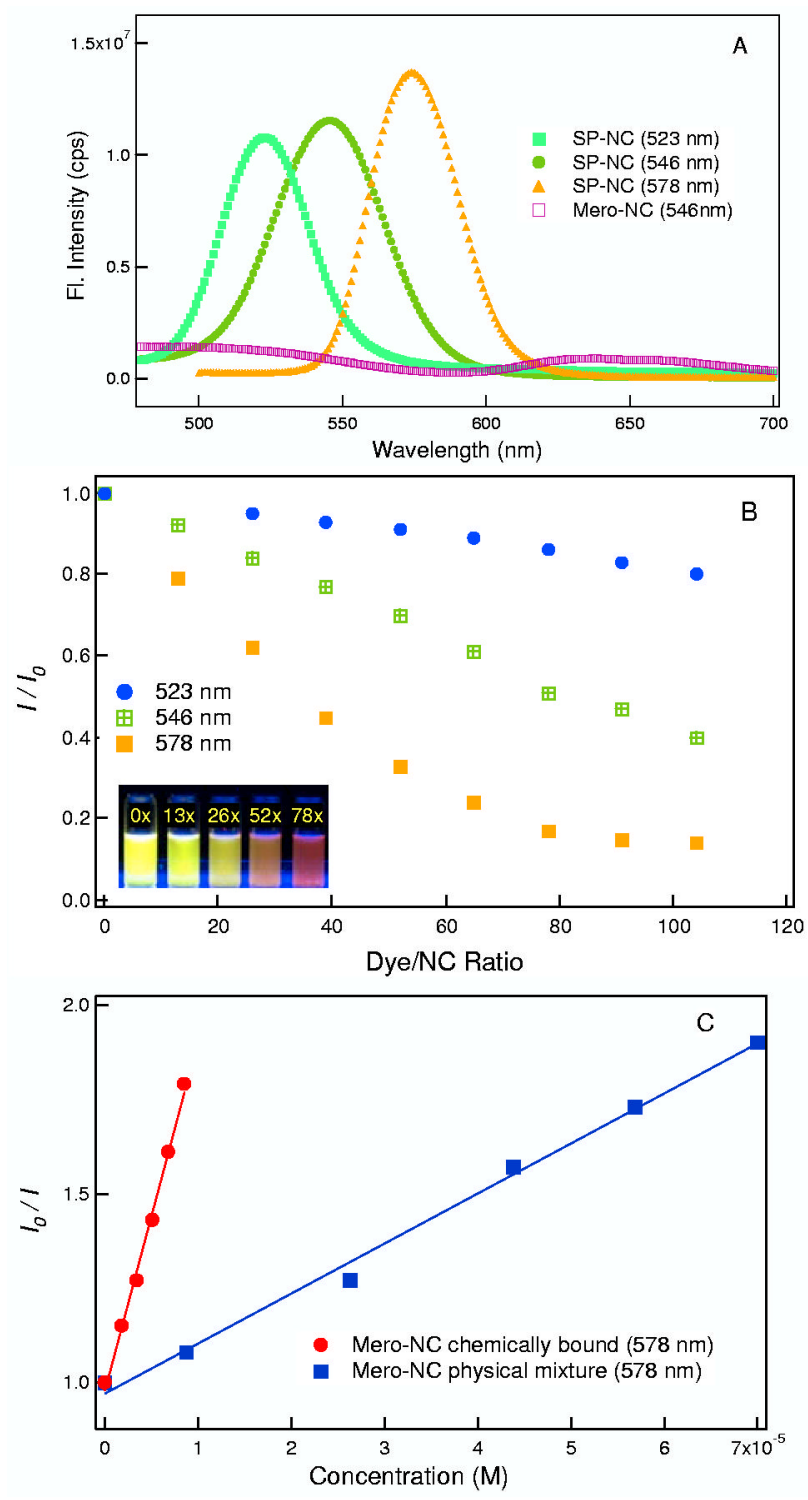

Figure 2.

(A) Size dependence of fluorescence spectra of spiropyran (SP) modified CdSe/ZnS core shell nanocrystals (NC). The fluorescence maximum of $4 \mathrm{~nm}$ (solid square), $5 \mathrm{~nm}$ (solid circles), and $6 \mathrm{~nm}$ (solid triangles) nanocrystals is at 523,546 , and $578 \mathrm{~nm}$, respectively. The merocyanine-modified nanocrystals have much reduced fluorescence intensity; an example shown (open squares) is a 5-nm mero-NC system; In all systems, the SP:NC ratios are 100:1. (B) Dependence of steady state fluorescence quenching of three different sizes of nanocrystals shown in (A) upon dye/NC ratio. The inset shows fluorescence color change of the $6 \mathrm{~nm} \mathrm{NC}$ at various ratio of the dye. (C) Stern-Volmer plots that compare the difference between bound merocyanine-nanocrystals and a physical mixture at various merocyanine concentrations. For all experiments, the nanocrystal concentration is $2.6 \times 10^{-7} \mathrm{M}$. 